\title{
Positive nuclear BAP1 immunostaining helps differentiate non- small cell lung carcinomas from malignant mesothelioma
}

\author{
Michele Carbone ${ }^{1}$, David Shimizu², Andrea Napolitano${ }^{1}$, Mika Tanji ${ }^{1}$, Harvey I. \\ Pass $^{3}$, Haining Yang ${ }^{1}$, Sandra Pastorino ${ }^{1}$ \\ ${ }^{1}$ Thoracic Oncology Program, University of Hawaii Cancer Center, Honolulu, HI, USA \\ ${ }^{2}$ Department of Pathology, Queen Medical Center, Honolulu, HI, USA \\ ${ }^{3}$ Department of Cardiothoracic Surgery, New York University, NYU Langone Medical Center, NY, USA \\ Correspondence to: Michele Carbone, email: mcarbone@cc.hawaii.edu \\ Keywords: mesothelioma, lung cancer, BAP1, differential diagnosis, immunohistochemistry \\ Received: May 20,2016 Accepted: June 13,2016 Published: July 18, 2016
}

\section{ABSTRACT}

The differential diagnosis between pleural malignant mesothelioma (MM) and lung cancer is often challenging. Immunohistochemical (IHC) stains used to distinguish these malignancies include markers that are most often positive in MM and less frequently positive in carcinomas, and vice versa. However, in about $10-20 \%$ of the cases, the IHC results can be confusing and inconclusive, and novel markers are sought to increase the diagnostic accuracy.

We stained 45 non-small cell lung cancer samples ( 32 adenocarcinomas and 13 squamous cell carcinomas) with a monoclonal antibody for BRCA1-associated protein 1 (BAP1) and also with an IHC panel we routinely use to help differentiate MM from carcinomas, which include, calretinin, Wilms Tumor 1, cytokeratin 5, podoplanin D240, pankeratin CAM5.2, thyroid transcription factor 1, Napsin-A, and p63. Nuclear BAP1 expression was also analyzed in 35 MM biopsies. All 45 non-small cell lung cancer biopsies stained positive for nuclear BAP1, whereas 22/35 (63\%) MM biopsies lacked nuclear BAP1 staining, consistent with previous data. Lack of BAP1 nuclear staining was associated with MM (two-tailed Fisher's Exact Test, $P=5.4 \times 10^{-11}$ ). Focal BAP1 staining was observed in a subset of samples, suggesting polyclonality. Diagnostic accuracy of other classical IHC markers was in agreement with previous studies. Our study indicated that absence of nuclear BAP1 stain helps differentiate MM from lung carcinomas. We suggest that BAP1 staining should be added to the IHC panel that is currently used to distinguish these malignancies.

\section{INTRODUCTION}

The incidence of malignant mesothelioma (MM) has increased exponentially in the US since the early ' 60 s, reaching 3,200 cases per year at the beginning of this century, and has remained stable since then [1]. Similarly, the incidence of lung cancer has increased exponentially during the past century, with currently over 200,000 cases of lung cancer diagnosed per year in the US [2]. Comparable trends have been observed since World War II in most countries, as a consequence of the increased use of asbestos, the most common cause of MM, and of cigarette smoking, the most common cause of lung cancer [3]. Moreover, asbestos and smoking synergize in causing lung cancer, and co-factors may increase asbestos carcinogenicity and MM [4-6]. Also, exposure to asbestos and other carcinogenic fibers present in the environment can cause MM and probably lung cancer [7-9].

$\mathrm{MM}$ and lung cancer patients are treated differently and have different prognosis, thus it is very important to properly diagnose these malignancies. This differential diagnosis is difficult, because MMs, in particular the epithelial subtype -which comprises about $70 \%$ of all MMs- can show a morphology similar to that of nonsmall cell lung carcinomas, and lung carcinosarcomas and spindle cell carcinomas can have a morphology similar to biphasic and sarcomatoid MMs. A set of immunohistochemical (IHC) stains helps distinguish these malignancies $[10,11]$ : more than $80 \%$ of epithelial MMs show nuclear stain for Wilms tumor protein (WT1) and 
calretinin, and show membranous stain for cytokeratin 5 (CK5). Lung squamous cell carcinomas (SCC) stain positive for CK5, and also for p63 (nuclear), and p40 (nuclear), the latter two markers are negative in MMs. Moreover, about $40 \%$ of SCC can also be positive for calretinin and show membranous stain for podoplanin (D2-40). Lung adenocarcinomas are instead positive for nuclear thyroid transcription factor 1 (TTF-1) and Napsin-A and for other cytoplasmic epithelial markers, such as the carcinoembryonic antigen (CEA), the Epithelial Related Antigen (MOC31), EpCam (BEREP4), etc., and rarely for calretinin and podoplanin (D2-40). Pankeratin CAM5.2 stains the membranes and the cytoplasm of the cells in both MMs and lung carcinomas.

When the results of the IHC stains fit the expectations, the diagnosis is usually straightforward. In about $10-20 \%$ of the cases, however, these malignancies can produce conflicting IHC results, with both MM and lung carcinoma markers being either positive or negative in the same tumor, or showing only a fraction of tumor cells being positive. Accordingly, there are still a large number of MMs that are misdiagnosed. In a large followup study that covered $25 \%$ of the French population, Goldberg et al. reported that the initial diagnosis of MM was confirmed only in $67 \%$ of cases [12]. Most recently, a review of Chinese MM confirmed the initial diagnosis, which was made with the support of a panel of IHC stains, in only $56 \%$ of cases [9]. In our experience, $10 \%$ or more of MMs, in the US, are misdiagnosed: these cases are often from hospitals and pathologists that rarely see patients with these types of tumors. Thus, too many patients worldwide continue to be misdiagnosed and consequently do not receive proper treatment for their malignancy.

Following studies of an epidemic of $\mathrm{MM}$ in Cappadocia that we linked to gene-environment interaction $[13,14]$, we discovered that germline truncating mutations in the BRCA1 associated protein-1 (BAPl) gene caused a very high incidence of MM, in some families in the US and abroad, in the absence of occupational exposure to asbestos $[15,16]$. Moreover, using a $\mathrm{BAP}^{+/-}$mouse model, we demonstrated that mice, carrying germline $B A P 1$ mutations, develop MM following exposure to very low doses of asbestos that rarely caused MM in wild-type mice [17]. Our data, confirmed and expanded by others, showed that germline $B A P 1$ mutations are also associated with uveal melanoma, renal cell carcinoma and other malignancies, causing a condition that we named "BAP1 cancer syndrome" [18]. BAP1 is a member of the ubiquitin C-terminal hydrolase subfamily of deubiquitinating enzymes and is found associated with multi-protein complexes that regulate cell cycle, differentiation, apoptosis, gluconeogenesis, and the DNA damage response $[18,19]$.

Somatic BAP1 mutations were also detected in sporadic (i.e., non familiar) MM [15, 20-22]. Using multidimensional genetic analyses, and IHC we demonstrated BAP1 inactivation in $>60 \%$ of sporadic
MMs [23], making $B A P 1$ the most commonly mutated gene in MM, a finding confirmed by others [24-26]. These findings underscore the pivotal role of BAP1 in MM. Recently, several studies reported that lack of nuclear BAP1 immunostaining helps differentiating benign reactive pleural effusion and pleurisy, which are BAP1 positive, from MMs, which are frequently BAP1 negative [27-30]. Other malignancies instead express normal levels of BAP1: for example BAP1 is expressed and detected by IHC in most pancreatic carcinomas [31], and in most peritoneal and gynecologic serous adenocarcinomas [32]. In 2012, Fan et al. detected BAP1 by Western blot studies in 103 non-small cell lung cancers, and correlated high expression with a good prognosis [33].

Here, we tested the hypothesis that BAP1 immunostain might help improve the accuracy of the differential diagnosis between MM, which often shows no BAP1 nuclear staining, and lung cancer, which we predicted to be BAP1 positive.

\section{RESULTS AND DISCUSSION}

All 45 non-small cell lung cancer samples analyzed -32 adenocarcinomas and $13 \mathrm{SCC}$ - stained positive for nuclear BAP1 (Table 1, Figure 1). Strong nuclear staining was detected in $\sim 100 \%$ of the tumor cells in all these tumors, except for 2 adenocarcinomas, in which some tumor areas contained cells showing BAP1 nuclear staining and some areas contained tumor nodules that were BAP1 negative. These cases are possibly due to presence of tumor subclones that had lost BAP1 expression, underscoring the risk of possible sample error if only minute needle biopsies, or tumor-arrays (slides with multiple minute fragments of different tumors) were to be examined [34].

In parallel, we stained 35 new MM samples for BAP1. Overall, BAP1 expression was entirely lost in $22 / 35(63 \%)$ of all MM samples. (Table 1, Figure 2). Focal BAP1 staining, suggestive of polyclonality [35], was observed in 6/20 (30\%) of epithelial MMs and 3/8 (37\%) of biphasic MMs. These results are consistent with our previous study in which, using integrated genetic approaches, coupled with IHC, we found that $66 \%$ of 92 MM studied displayed a lack of nuclear BAP1 staining [23]. A re-analysis of these cases revealed that, among the 60/92 MMs that were of the epithelial-type, only 14 (23\%) were BAP1 positive and 1 additional MM showed focal nuclear positivity. Among the 32/92 non-epithelial MMs (i.e., biphasic and sarcomatoid), $11(30 \%)$ were BAP1 positive, and $5(15 \%)$ showed focal positivity.

In addition, we compared a panel of "classical" IHC stains used to distinguish MM and lung cancer in these 45 non-small cell lung cancer samples and in $10 \mathrm{MM}$ samples (Table 2). MM cells were mostly positive for WT1 (nuclear), calretinin (nuclear and cytoplasmic), D240, CK5, and CAM5.2, and the same cells were negative for TTF-1, p63, and Napsin-A. Lung adenocarcinoma 
Table 1: Immunoreactivity of nuclear BAP1 in malignant mesothelioma and non-small cell lung cancer

\begin{tabular}{|c|c|c|c|c|c|c|c|}
\hline \multirow{2}{*}{$\begin{array}{l}\text { Tumor Type } \\
\text { Histology }\end{array}$} & \multicolumn{4}{|c|}{ Malignant Mesothelioma } & \multicolumn{3}{|c|}{ Non-small cell lung cancer } \\
\hline & Epithelial & Biphasic & Sarc & Total & Adeno & $\mathrm{SCC}$ & Total \\
\hline Sample no. & 20 & 8 & 7 & 35 & 32 & 13 & 45 \\
\hline BAP1 Neg & $13(65 \%)$ & $4(50 \%)$ & $5(71 \%)$ & $22(63 \%)$ & 0 & 0 & 0 \\
\hline BAP1 Pos & $1(5 \%)$ & $1(13 \%)$ & $2(29 \%)$ & $4(11 \%)$ & $30(94 \%)$ & $13(100 \%)$ & $43(96 \%)$ \\
\hline BAP1 Focal & $6(30 \%)$ & $3(37 \%)$ & 0 & $9(26 \%)$ & $2(6 \%)$ & 0 & $2(4 \%)$ \\
\hline
\end{tabular}

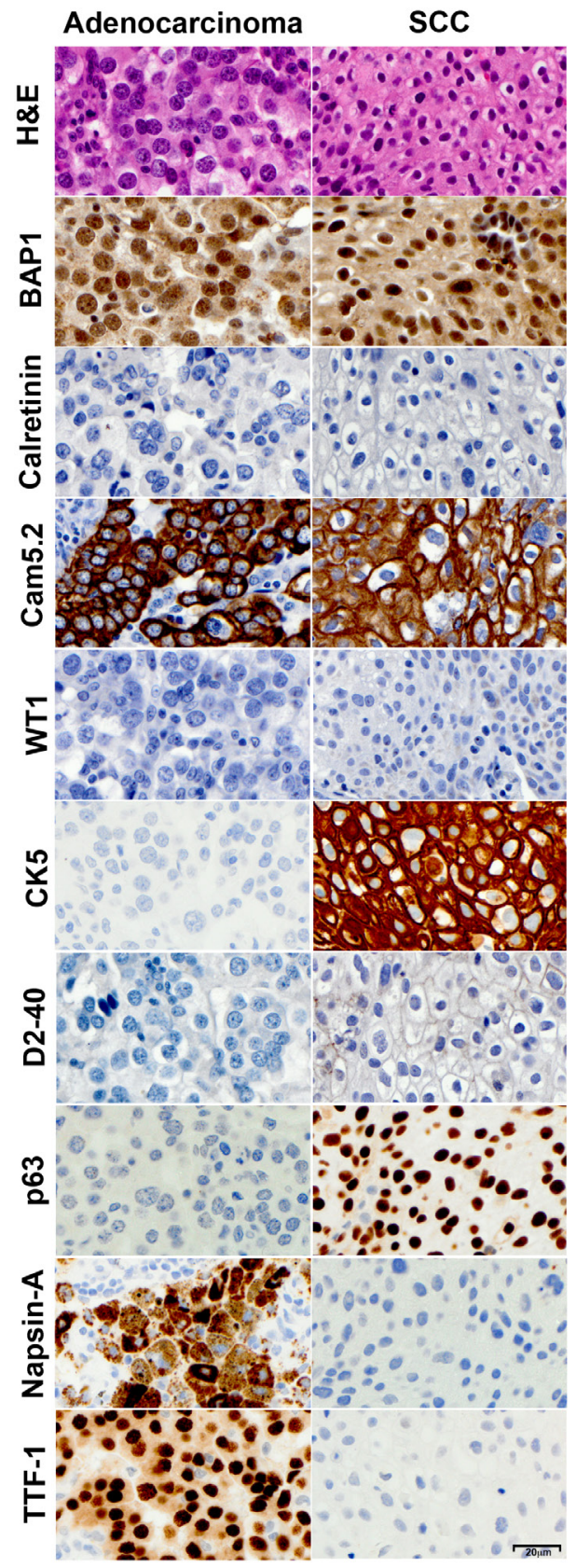

Figure 1: Immunohistochemical characterization of non-small cell lung cancers. Representative lung adenocarcinoma (left) and SCC (right) were stained with Hematoxylin and Eosin, and for expression of BAP1, calretinin, CAM5.2, WT1, CK5, D2-40, p63, Napsin-A and TTF-1. Note the strong BAP1 nuclear staining in both specimens. All photomicrographs were taken at 400x original magnification; representative size bar is shown on the bottom right panel. 
cells were always positive for TTF-1, Napsin-A, and CAM5.2; and negative for nuclear WT1 and D2-40 and $6 \%$ of them stained for calretinin (nuclear and cytoplasmic focal staining). Tumor cells in SCC were almost uniformly positive for CK5, CAM5.2 and p63, and negative for WT1, TTF-1 and Napsin-A; Calretinin and D2-40 were focally positive respectively in $23 \%$ and $77 \%$ of them (Table 2, Figures 1-2). These findings are in agreement with previous studies $[10,11]$ indicating that WT1 nuclear positivity is the most specific positive marker for MM, while TTF-1 and Napsin-A are most specific for lung adenocarcinoma, and p63 and p40 are specific markers for lung SCC. We found that calretinin, a marker often used in support of the diagnosis of MM, is certainly a very sensitive MM marker, but because it stains also a large proportion of SCC and some adenocarcinomas it is insufficient, per se, to establish the diagnosis. It has been our experience that, at times, misdiagnoses of MM were based on an incomplete, limited, set of IHC stains showing positivity for calretinin. The more specific marker WT-1 stains about $80 \%$ of the epitelioid MM, and about $50 \%$ of sarcomatoid MMs. We found that D2-40 stains MM but

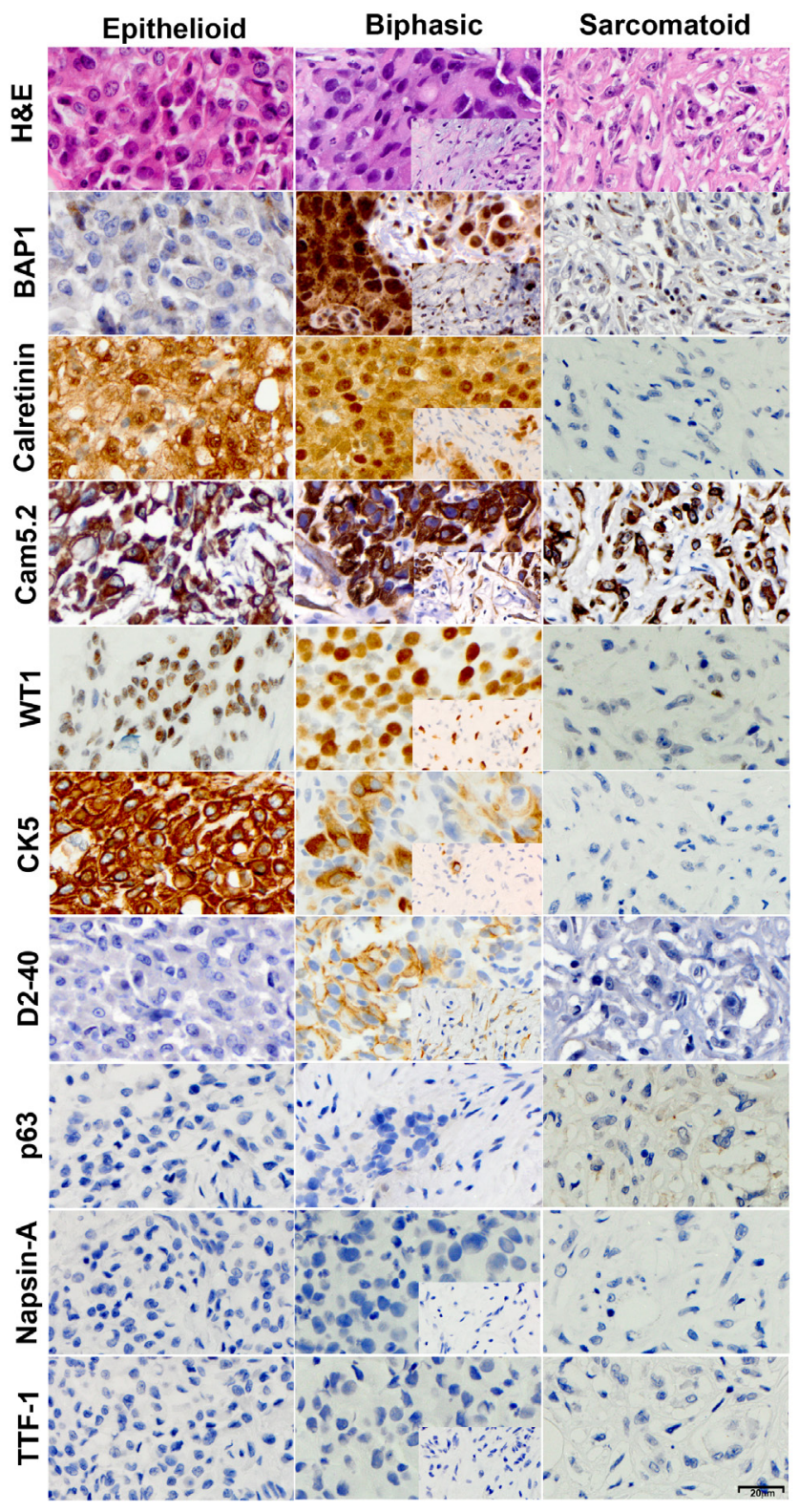

Figure 2: Immunohistochemical characterization of malignant mesotheliomas. Representative epithelioid (left), biphasic (center) and sarcomatoid (right) specimens were stained with Hematoxylin and Eosin, and for expression of BAP1, calretinin, CAM5.2, WT1, CK5, D2-40, p63, Napsin-A and TTF-1. Inserts depict the spindle component within the biphasic tumor. Note lack of BAP1 nuclear staining in the epithelioid and sarcomatoid specimens. All photomicrographs were taken at 400x original magnification; representative size bar is shown on the bottom right panel. 
Table 2: Immunoreactivity of other markers in malignant mesothelioma and non-small cell lung cancer

\begin{tabular}{|c|c|c|c|c|c|c|c|}
\hline \multirow{2}{*}{$\begin{array}{l}\text { Tumor Type } \\
\text { Histology }\end{array}$} & \multicolumn{4}{|c|}{ Malignant Mesothelioma } & \multicolumn{3}{|c|}{ Non-small cell lung cancer } \\
\hline & Epithelial & Biphasic & Sarc & Total & Adeno & SCC & Total \\
\hline Sample no. & 5 & 1 & 4 & 10 & 32 & 13 & 45 \\
\hline Calretinin & $5(100 \%)$ & $1(100 \%)$ & $3(75 \%)$ & $9(90 \%)$ & $2(6 \%)$ & $3^{\$}(23 \%)$ & $5(11 \%)$ \\
\hline Cam5.2 & $5(100 \%)$ & $1(100 \%)$ & $4(100 \%)$ & $10(100 \%)$ & $32(100 \%)$ & $\begin{array}{c}13 * * * \\
(100 \%)\end{array}$ & $45(100 \%)$ \\
\hline D2-40 & $4^{\#}(100 \%)$ & $1 *(100 \%)$ & $3^{\$}(75 \%)$ & $8(80 \%)$ & 0 & $10^{\$}(77 \%)$ & $10(4 \%)$ \\
\hline WT1 & $5(100 \%)$ & $1(100 \%)$ & $2(50 \%)$ & $8(80 \%)$ & 0 & 0 & 0 \\
\hline CK 5 & $5^{*}(100 \%)$ & $1 *(100 \%)$ & $3(75 \%)$ & $9(90 \%)$ & $2 *(6 \%)$ & $13(100 \%)$ & $15(35 \%)$ \\
\hline p63 & 0 & 0 & 0 & 0 & $4^{\$}(12 \%)$ & $13(100 \%)$ & $17(38 \%)$ \\
\hline TTF-1 & 0 & 0 & 0 & 0 & $31 * *(97 \%)$ & $1(8 \%)$ & $32(71 \%)$ \\
\hline Napsin-A & 0 & 0 & 0 & 0 & $31 * *(97 \%)$ & $1(8 \%)$ & $32(71 \%)$ \\
\hline
\end{tabular}

\# for one sample D2-40 staining was not available; three out of the four positive MM samples showed focal staining.

* focal staining was observed in one positive sample.

** focal staining was observed in two positive samples.

*** focal staining was observed in three positive samples.

$\$$ focal staining was observed in all the positive samples.

also lung carcinomas and therefore, although sensitivity is high, as most MMs stain for D2-40, the specificity is low.

In summary, we found that lack of BAP1 nuclear staining was preferentially associated with MM (twotailed Fisher's Exact Test, $P=5.4 \times 10^{-11}$ ) and that instead lack of nuclear staining is not found in lung carcinomas, or at least is quite rare, since in our study 45/45 lung cancers stained for nuclear BAP1. In support of our findings, genomic data from the TCGA collaboration on lung cancer showed that mutations of $B A P 1$ are extremely rare in non-small cell lung cancer: frame-shift mutations and deletions that would result in loss of BAP1 nuclear staining were present in less than $1 \%$ of more than 400 lung adenocarcinomas [36-38] and 178 SCC studied [39]. Moreover, this June 2016, after our paper was submitted for publication, Andrici J et al., reported that out of 155 lung adenocarcinomas and 72 lung SCC, only one had lost BAP1 expression [40]. These Authors, quoting previous literature, noted: "this finding increases the specificity of loss of expression for BAP1 for the diagnosis of mesothelioma" [40]. Although the paper by Andrici et al. did not include a parallel analysis of MM biopsies, their IHC results independently support our findings and conclusions. Together, these findings, justify including BAP1 in the panel of antibodies used to differentiate lung cancer from MM.

\section{MATERIALS AND METHODS}

All investigations described in this study have been performed in accordance with the principles embodied in the Declaration of Helsinki. Written informed consent was received from all patients. Collection and use of patient information and samples were approved by the IRB of the University of Hawaii (IRB no. 14406). We studied 32 primary lung adenocarcinomas, 13 primary lung SCC and $10 \mathrm{MM}$ biopsies, which were diagnosed at the Queens Medical Center, Honolulu, Hawaii. We also analysed 25 MM biopsies from the New York University New York, New York, (all calretinin and WT1 positive and negative for epithelial markers) for a total of $35 \mathrm{MM}$ biopsies. Of these, 20 were of the epithelial type, 8 were biphasic and 7 were sarcomatoid.

IHC was performed on formalin fixed paraffin embedded tissue sections, using the avidin-biotinperoxidase complex method in a DAKO-autostainer (Carpinteria, CA, USA). The primary antibodies used in this study were: BAP1 (Clone C-4, Santa Cruz Biotechnology); p63 (clone 4A4, Biocare); Napsin A (clone BC15, Biocare); TTF1 (clone SPT24, Leica); CK5 (clone XM26, Leica); WT1 (clone WT49, Leica); Calretinin (clone CAL6, Leica); D2-40, clone D2-40, DAKO); Cam5.2 (clone Cam 5.2, BD Biosciences).

All diagnoses were made on hematoxylin-eosin stained sections combined with immunohistochemical and clinical features. Expert pathologists in pleural pathology, independently evaluated the biopsies (M.C., D.S and H.I.P.).

IHC of BAP1 protein expression was performed as described [15, 23, 41], using a mouse monoclonal antiBAP1antibody (C-4: Santa Cruz Biotechnology, TX). This antibody recognizes the epitope between a.a. 430 and 739; therefore, it detects BAP1 wild-type and mutant forms that retain the nuclear localization signal (NLS). 
We extensively validated this antibody for the detection of nuclear BAP1 on a number of normal human pleural samples -all showing nuclear staining in $100 \%$ of pleural cells, as well as on MM-derived cell lines [41]. Statistical analysis was performed applying the two-tailed Fisher's Exact Test.

\section{CONFLICTS OF INTEREST}

$\mathrm{MC}$ has pending patent applications on BAP1 and provides consultation for MM expertise and diagnosis. The remaining authors have declared that no conflicts of interests exists.

\section{GRANT SUPPORT}

This study was supported by the NCI-R01 CA198138 to M.C.; by the NCI-R01 CA160715, to H.Y.; and by the University of Hawai'i Foundation, which received an unrestricted gift to support MM research from Honeywell International Inc. to M.C., and from the United-4-A-Cure, Riviera Foundation to M.C. and H.Y; and by donations to support MM research from Belluck and Fox, to H.I.P.

\section{REFERENCES}

1. Henley SJ, Larson $\mathrm{TC}, \mathrm{Wu} \mathrm{M}$, Antao VC, Lewis M, Pinheiro GA, Eheman C. Mesothelioma incidence in 50 states and the District of Columbia, United States, 20032008. Int J Occup Environ Health. 2013; 19: 1-10. doi: 10.1179/2049396712Y.0000000016.

2. U.S. Cancer Statistics Working Group. (2015). United States Cancer Statistics: 1999-2012 Incidence and Mortality Web-based Report. (Atlanta, U.S: Department of Health and Human Services, Centers for Disease Control and Prevention and National Cancer Institute).

3. Delgermaa V, Takahashi K, Park EK, Le GV, Hara T, Sorahan T. Global mesothelioma deaths reported to the World Health Organization between 1994 and 2008. Bull World Health Organ. 2011; 89: 716-24, 24A-24C. doi: 10.2471/BLT.11.086678.

4. Carbone M. Simian virus 40 and human tumors: It is time to study mechanisms. J Cell Biochem. 1999; 76: 189-93.

5. Carbone M, Klein G, Gruber J, Wong M. Modern criteria to establish human cancer etiology. Cancer Res. 2004; 64: 5518-24. doi: 10.1158/0008-5472.CAN-04-0255.

6. Gazdar AF, Carbone M. Molecular pathogenesis of malignant mesothelioma and its relationship to simian virus 40. Clin Lung Cancer. 2003; 5: 177-81. doi: 10.3816/ CLC.2003.n.031.

7. Baumann F, Buck BJ, Metcalf RV, McLaurin BT, Merkler DJ, Carbone M. The Presence of Asbestos in the Natural Environment is Likely Related to Mesothelioma in Young Individuals and Women from Southern
Nevada. J Thorac Oncol. 2015; 10: 731-7. doi: 10.1097/ JTO.0000000000000506.

8. Carbone M, Baris YI, Bertino P, Brass B, Comertpay S, Dogan AU, Gaudino G, Jube S, Kanodia S, Partridge CR, Pass HI, Rivera ZS, Steele I, et al. Erionite exposure in North Dakota and Turkish villages with mesothelioma. Proc Natl Acad Sci U S A. 2011; 108: 13618-23. doi: 10.1073/ pnas. 1105887108 .

9. Carbone M, Kanodia S, Chao A, Miller A, Wali A, Weissman D, Adjei A, Baumann F, Boffetta P, Buck B, de Perrot M, Dogan AU, Gavett S, et al. Consensus Report of the 2015 Weinman International Conference on Mesothelioma. J Thorac Oncol. 2016; 11: 1246-62. doi: 10.1016/j.jtho.2016.04.028.

10. Husain AN, Colby TV, Ordonez NG, Krausz T, Borczuk A, Cagle PT, Chirieac LR, Churg A, Galateau-Salle F, Gibbs AR, Gown AM, Hammar SP, Litzky LA, et al. Guidelines for pathologic diagnosis of malignant mesothelioma: a consensus statement from the International Mesothelioma Interest Group. Arch Pathol Lab Med. 2009; 133: 1317-31. doi: 10.1043/1543-2165-133.8.1317.

11. Comin CE, Novelli L, Cavazza A, Rotellini M, Cianchi F, Messerini L. Expression of thrombomodulin, calretinin, cytokeratin 5/6, D2-40 and WT-1 in a series of primary carcinomas of the lung: an immunohistochemical study in comparison with epithelioid pleural mesothelioma. Tumori. 2014; 100: 559-67. doi: 10.1700/1660.18182.

12. Goldberg M, Imbernon E, Rolland P, Gilg Soit Ilg A, Saves M, de Quillacq A, Frenay C, Chamming's S, Arveux P, Boutin C, Launoy G, Pairon JC, Astoul P, et al. The French National Mesothelioma Surveillance Program. Occup Environ Med. 2006; 63: 390-5. doi: 10.1136/ oem.2005.023200.

13. Roushdy-Hammady I, Siegel J, Emri S, Testa JR, Carbone M. Genetic-susceptibility factor and malignant mesothelioma in the Cappadocian region of Turkey. Lancet. 2001; 357: 444-5. doi: 10.1016/S0140-6736(00)04013-7.

14. Carbone M, Emri S, Dogan AU, Steele I, Tuncer M, Pass HI, Baris YI. A mesothelioma epidemic in Cappadocia: scientific developments and unexpected social outcomes. Nat Rev Cancer. 2007; 7: 147-54. doi: 10.1038/nrc2068.

15. Testa JR, Cheung M, Pei J, Below JE, Tan Y, Sementino E, Cox NJ, Dogan AU, Pass HI, Trusa S, Hesdorffer M, Nasu M, Powers A, et al. Germline BAP1 mutations predispose to malignant mesothelioma. Nat Genet. 2011; 43: 1022-5. doi: 10.1038/ng.912.

16. Carbone M, Flores EG, Emi M, Johnson TA, Tsunoda T, Behner D, Hoffman H, Hesdorffer M, Nasu M, Napolitano A, Powers A, Minaai M, Baumann F, et al. Combined Genetic and Genealogic Studies Uncover a Large BAP1 Cancer Syndrome Kindred Tracing Back Nine Generations to a Common Ancestor from the 1700s. PLoS Genet. 2015; 11: e1005633. doi: 10.1371/journal.pgen.1005633.

17. Napolitano A, Pellegrini L, Dey A, Larson D, Tanji M, Flores EG, Kendrick B, Lapid D, Powers A, Kanodia S, 
Pastorino S, Pass HI, Dixit V, et al. Minimal asbestos exposure in germline BAP1 heterozygous mice is associated with deregulated inflammatory response and increased risk of mesothelioma. Oncogene. 2016; 35: 1996-2002. doi: 10.1038/onc.2015.243.

18. Carbone M, Yang H, Pass HI, Krausz T, Testa JR, Gaudino G. BAP1 and cancer. Nat Rev Cancer. 2013; 13: 153-9.

19. Mashtalir N, Daou S, Barbour H, Sen NN, Gagnon J, Hammond-Martel I, Dar HH, Therrien M, Affar el B. Autodeubiquitination protects the tumor suppressor BAP1 from cytoplasmic sequestration mediated by the atypical ubiquitin ligase UBE2O. Mol Cell. 2014; 54: 392-406. doi: 10.1016/j.molcel.2014.03.002.

20. Bott M, Brevet M, Taylor BS, Shimizu S, Ito T, Wang L, Creaney J, Lake RA, Zakowski MF, Reva B, Sander C, Delsite R, Powell S, et al. The nuclear deubiquitinase BAP1 is commonly inactivated by somatic mutations and $3 \mathrm{p} 21.1$ losses in malignant pleural mesothelioma. Nat Genet. 2011; 43: 668-72. doi: 10.1038/ng.855.

21. Yoshikawa Y, Sato A, Tsujimura T, Emi M, Morinaga T, Fukuoka K, Yamada S, Murakami A, Kondo N, Matsumoto S, Okumura Y, Tanaka F, Hasegawa S, et al. Frequent inactivation of the BAP1 gene in epithelioid-type malignant mesothelioma. Cancer Sci. 2012; 103: 868-74. doi: 10.1111/j.1349-7006.2012.02223.x.

22. Arzt L, Quehenberger F, Halbwedl I, Mairinger T, Popper HH. BAP1 protein is a progression factor in malignant pleural mesothelioma. Pathol Oncol Res. 2014; 20: 145-51. doi: 10.1007/s12253-013-9677-2.

23. Nasu M, Emi M, Pastorino S, Tanji M, Powers A, Luk H, Baumann F, Zhang YA, Gazdar A, Kanodia S, Tiirikainen M, Flores E, Gaudino G, et al. High Incidence of Somatic BAP1 alterations in sporadic malignant mesothelioma. J Thorac Oncol. 2015; 10: 565-76. doi: 10.1097/ JTO.0000000000000471.

24. Guo G, Chmielecki J, Goparaju C, Heguy A, Dolgalev I, Carbone M, Seepo S, Meyerson M, Pass HI. Wholeexome sequencing reveals frequent genetic alterations in BAP1, NF2, CDKN2A, and CUL1 in malignant pleural mesothelioma. Cancer Res. 2015; 75: 264-9. doi: 10.1158/0008-5472.CAN-14-1008.

25. Lo Iacono M, Monica V, Righi L, Grosso F, Libener R, Vatrano S, Bironzo P, Novello S, Musmeci L, Volante M, Papotti M, Scagliotti GV. Targeted next-generation sequencing of cancer genes in advanced stage malignant pleural mesothelioma: a retrospective study. J Thorac Oncol. 2015; 10: 492-9. doi: 10.1097/JTO.0000000000000436.

26. Bueno R, Stawiski EW, Goldstein LD, Durinck S, De Rienzo A, Modrusan Z, Gnad F, Nguyen TT, Jaiswal BS, Chirieac LR, Sciaranghella D, Dao N, Gustafson CE, et al. Comprehensive genomic analysis of malignant pleural mesothelioma identifies recurrent mutations, gene fusions and splicing alterations. Nat Genet. 2016; 48: 407-16. doi: 10.1038/ng.3520.
27. Sheffield BS, Hwang HC, Lee AF, Thompson K, Rodriguez S, Tse $\mathrm{CH}$, Gown AM, Churg A. BAP1 immunohistochemistry and p16 FISH to separate benign from malignant mesothelial proliferations. Am J Surg Pathol. 2015; 39: 977-82. doi: 10.1097/ PAS.0000000000000394.

28. McGregor SM, Dunning R, Hyjek E, Vigneswaran W, Husain AN, Krausz T. BAP1 facilitates diagnostic objectivity, classification, and prognostication in malignant pleural mesothelioma. Hum Pathol. 2015; 46: 1670-8. doi: 10.1016/j.humpath.2015.06.024.

29. Andrici J, Sheen A, Sioson L, Wardell K, Clarkson A, Watson N, Ahadi MS, Farzin M, Toon CW, Gill AJ. Loss of expression of BAP1 is a useful adjunct, which strongly supports the diagnosis of mesothelioma in effusion cytology. Mod Pathol. 2015; 28: 1360-8. doi: 10.1038/ modpathol.2015.87.

30. Cigognetti M, Lonardi S, Fisogni S, Balzarini P, Pellegrini V, Tironi A, Bercich L, Bugatti M, Rossi G, Murer B, Barbareschi M, Giuliani S, Cavazza A, et al. BAP1 (BRCA1-associated protein 1) is a highly specific marker for differentiating mesothelioma from reactive mesothelial proliferations. Mod Pathol. 2015; 28: 1043-57. doi: 10.1038/modpathol.2015.65.

31. Tayao M, Andrici J, Farzin M, Clarkson A, Sioson L, Watson N, Chua TC, Sztynda T, Samra JS, Gill AJ. Loss of BAP1 Expression Is Very Rare in Pancreatic Ductal Adenocarcinoma. PLoS One. 2016; 11: e0150338. doi: 10.1371/journal.pone.0150338.

32. Andrici J, Jung J, Sheen A, D'Urso L, Sioson L, Pickett J, Parkhill TR, Verdonk B, Wardell KL, Singh A, Clarkson A, Watson N, Toon CW, et al. Loss of BAP1 expression is very rare in peritoneal and gynecologic serous adenocarcinomas and can be useful in the differential diagnosis with abdominal mesothelioma. Hum Pathol. 2016; 51: 9-15. doi: 10.1016/j.humpath.2015.12.012.

33. Fan LH, Tang LN, Yue L, Yang Y, Gao ZL, Shen Z. BAP1 is a good prognostic factor in advanced non-small cell lung cancer. Clin Invest Med. 2012; 35: E182-9.

34. Gerlinger M, Rowan AJ, Horswell S, Larkin J, Endesfelder D, Gronroos E, Martinez P, Matthews N, Stewart A, Tarpey P, Varela I, Phillimore B, Begum S, et al. Intratumor heterogeneity and branched evolution revealed by multiregion sequencing. N Engl J Med. 2012; 366: 883-92. doi: 10.1056/NEJMoa1113205.

35. Comertpay S, Pastorino S, Tanji M, Mezzapelle R, Strianese O, Napolitano A, Baumann F, Weigel T, Friedberg J, Sugarbaker P, Krausz T, Wang E, Powers A, et al. Evaluation of clonal origin of malignant mesothelioma. J Transl Med. 2014; 12: 301. doi: 10.1186/ s12967-014-0301-3.

36. Imielinski M, Berger AH, Hammerman PS, Hernandez B, Pugh TJ, Hodis E, Cho J, Suh J, Capelletti M, Sivachenko A, Sougnez C, Auclair D, Lawrence MS, et al. Mapping the hallmarks of lung adenocarcinoma with massively parallel 
sequencing. Cell. 2012; 150: 1107-20. doi: 10.1016/j. cell.2012.08.029.

37. Rizvi NA, Hellmann MD, Snyder A, Kvistborg P, Makarov V, Havel JJ, Lee W, Yuan J, Wong P, Ho TS, Miller ML, Rekhtman N, Moreira AL, et al. Cancer immunology. Mutational landscape determines sensitivity to PD-1 blockade in non-small cell lung cancer. Science. 2015; 348: 124-8. doi: 10.1126/science.aaa1348.

38. Cancer Genome Atlas Research N. Comprehensive molecular profiling of lung adenocarcinoma. Nature. 2014; 511: 543-50. doi: 10.1038/nature13385.
39. Cancer Genome Atlas Research N. Comprehensive genomic characterization of squamous cell lung cancers. Nature. 2012; 489: 519-25. doi: 10.1038/nature11404.

40. Andrici J, Parkhill TR, Jung J, Wardell KL, Verdonk B, Singh A, Sioson L, Clarkson A, Watson N, Sheen A, Farzin $\mathrm{M}$, Toon CW, Gill AJ. Loss of expression of BAP1 is very rare in non-small cell lung carcinoma. Pathology. 2016. doi: 10.1016/j.pathol.2016.03.005.

41. Carbone M, Ferris LK, Baumann F, Napolitano A, Lum CA, Flores EG, Gaudino G, Powers A, Bryant-Greenwood P, Krausz T, Hyjek E, Tate R, Friedberg J, et al. BAP1 cancer syndrome: malignant mesothelioma, uveal and cutaneous melanoma, and MBAITs. J Transl Med. 2012; 10: 179. doi: 10.1186/1479-5876-10-179. 